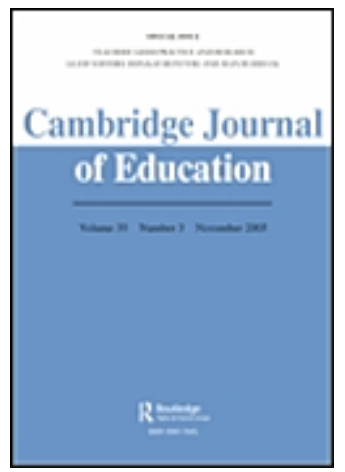

Primary school teachers' restricted and elaborated anger

\begin{tabular}{|r|l|}
\hline Journal: & Cambridge Journal of Education \\
\hline Manuscript ID: & Draft \\
\hline Manuscript Type: & Original Article \\
\hline Keywords: & Teachers, Primary Education, Cognitive Psychology \\
\hline \multicolumn{2}{|l}{} \\
\hline
\end{tabular}

S) ScholaroNE 


\title{
Primary School Teachers' Restricted and Elaborated Anger
}

\begin{abstract}
This article examines the cognitive appraisals associated with the emotion of anger based on interviews with teachers. An analysis of these appraisals demonstrated that teachers experienced different forms of anger depending on whether they were relating to other adults or their pupils. Anger in relation to children was based on persistent goal blockage, the build up frustration and the assignment of blame. Such anger, referred to here as restricted anger, was expressed at the time and seemed to involved limited cognitive elaboration. By contrast, anger in relation to parents and colleagues was associated with blaming others for having brought about an unfair/unjust outcome and a perceived threat to self. Such anger, referred to here as elaborated anger, was not displayed immediately but appeared to be cognitively dwelled upon and maintained. These two forms of anger and their appraisals are examined and their implications for teachers and teaching considered.
\end{abstract}

Keywords: emotions, anger, cognitive psychology, primary education, teachers

\section{Introduction}

Recent research on teachers and teaching has become increasingly sensitive to the central role that emotions play in teachers' working lives. In particular, educational researchers have noted how exploring teachers' emotional experiences can provide them with the context to examine teachers' views about themselves and their identities (Hargreaves, 1998; Kelchtermans, 2005; Lasky, 2005; Nias, 1996; van Veen \& Sleegers, 2006; Zembylas, 2003). In addition, Poulou and Norwich (2002) have explored the relationship between teachers' thoughts and beliefs, the emotions that they experience and their potential actions in response to pupils who display emotional and behavioural difficulties. 
This article specifically examines teachers' anger in relation to other adults and their pupils. Sutton (2000) highlighted the relevance of this emotion to teachers' working lives by documenting how middle school teachers in the United States experience frustration and anger more often in class than other emotions. Drawing on appraisal theory Sutton (2002) then investigated the possible causes for these negative emotions and the impact that they may have on teaching. She found that approximately two thirds of incidents resulting in frustration and anger were triggered by students' misbehaviour and the appraisal of goal blockage, as they prevented the teacher from teaching the class. Recently, Sutton also investigated the extent to which teachers self regulate the experience of these negative emotions (Sutton, 2004, 2007). She concluded that teachers attempt to regulate their feelings of frustration and anger in class both by their actions and by mentally reflecting upon their current emotional state.

Besides Sutton's suggestion that anger is often experienced in relation to pupil misbehaviour and the perception of goal blockage, Liljestrom, Roulston and DeMarrais (2007) propose that female teachers in the United States most often feel angry when they perceive themselves to have been hindered from attaining their moral objectives. Participants reported experiencing anger most often when they perceived themselves to have been prevented from pursuing moral imperatives, such as caring for the whole child, developing relationships with their pupils, or providing them with life skills. They held constraints within the education system and the lack of support from management responsible for the obstruction of their moral objectives. On occasion teachers also reported feeling angry with parents for not providing sufficient basic care for their children.

\section{Theoretical Background: Cognitive Appraisal Theory}

Similar to Sutton's research this investigation draws on cognitive appraisal theory to explain variation in emotional responses. Appraisal theory assumes a close relationship 
between individuals' cognitive interpretation of events and the emotions that they experience. According to appraisal theory the different emotions a person experiences are predominantly based on variations in his/her cognitive evaluation (or appraisal) of situations and their potential consequences (Lazarus, 1991). Hence, each emotion is thought to have a number of cognitive appraisals associated with it. Appraisal research methods have predominantly consisted of a survey design (for instance, Ellsworth \& Smith, 1988; Roseman, Antoniou, \& Jose, 1996; Scherer, 1993; Smith \& Lazarus, 1993). In these studies a relatively large number of participants were asked to complete questionnaires that asked them to recall a recent emotional event where they predominantly experienced a particular emotion, such as anger, guilt or sadness. They were then required to answer a series of questions that focussed on potentially relevant cognitive appraisals. The purpose of these investigations was to verify the validity of a number of set cognitive appraisals for a specific group of emotions. The most notable observation that can be made when reviewing the findings of appraisal research is the high degree of consensus in the appraisals proposed by the different researchers for basic emotions such as anger, fear, sadness or joy. For instance, all appraisal researchers agree that anger includes the appraisals of holding someone else responsible for a negative outcome. Besides such agreement on many appraisals associated with basic emotions, however, there are also some substantive differences as certain appraisals are only considered to be of relevance by some researchers. For instance, Lazarus (1991) is the only researcher who maintains that the enhancement of one's self or ego identity contributes to the emotion of pride.

As Schorr (2001) points out, early representations of the cognitive appraisal process depicted the relationship between cognition and emotions as sequential and linear where the cognitive appraisal of a situation precedes an emotional response. In contrast, more recent reconceptualizations of the appraisal process acknowledge that a person is usually already in an 
emotional state when s/he appraises a situation and that this has a biasing influence on how s/he cognitively appraises the event (Frijda \& Zeelenberg, 2001; Scherer, 2001b). In other words, while a specific and differentiated emotional response depend on a person's cognitive appraisals, the appraisals pathway adopted at that time is most likely influenced or even determined by the individual's current emotional state. For instance, when a person is already feeling happy then s/he is likely to appraise situations differently to when s/he is feeling anxious or sad. Of particular importance in these interactive rather than linear representations of cognitive appraisal is that most emotional responses are based on 'hot' cognitive appraisal that is already under the influence of affective biasing. Hence, a person rarely appraises a situation dispassionately, but almost always under the influence of an emotional state that may vary from an undifferentiated negative or positive mood to a strong emotional reaction to what has occurred before.

In relation to anger appraisal theorists agree that this emotion is associated with the core appraisal of blaming someone for a negative outcome that has substantial relevance to the individual (Ellsworth \& Smith, 1988; Lazarus, 1991; Roseman, 2001; Scherer, 2001a). In addition, Roseman (2001), Scherer (2001) and Lazarus (1991) suggest that anger is associated with the appraisal of potentially being able to control the situation and its outcome. A person is therefore more likely to become angry if s/he thinks that she may be able to influence events and their consequences. Alongside these appraisals Ellsworth and Smith (1988) and Mikula, Scherer and Athenstaed (1998) propose that anger is associated with the appraisal of another person's actions being unfair and/or illegitimate and Lazarus (1991) with a need to preserve one's self or ego identity.

Yet, despite the identification of abstract appraisals for specific emotions such as anger appraisal research has made limited impact on the study of emotions at work or other social settings. Shweder (1993) maintains that one reason for this is that while appraisal 
research has been successful in the identification of abstract appraisals it has been less effective in identifying appraisals that are relevant to particular social contexts. In other words, the appraisals identified from appraisal research are so inclusive, abstract and remote from their context that they lack substantive meaning and are of limited relevance when considering real life situations. In the case of anger, appraisal research has also identified abstract appraisals which it is argued here are of limited value to educational research as they do not provide substantive insight into thoughts and emotions within specific educational settings. Thus keeping in mind the need to also study cognitive appraisal at a more contextual and concrete level, this study investigated the substantive meanings of the abstract appraisals identified in earlier research for specific emotions, within the context of primary school teachers' working lives. To this end the present investigation has adopted a qualitative approach as it allows for an in-depth exploration and analysis of the cognitive appraisals associated with primary school teachers' emotions.

\section{The Present Study}

This article reports on some of the findings of a study on teachers' thoughts and emotions conducted in eight inner city primary schools in England between February and July 2005. The overall project also included a secondary school, but the findings from this school are not included in this paper. The investigation involved detailed interviews with 52 primary school teachers about emotional events that they had experienced over the previous two weeks. The approach adopted is based on the research methods applied in appraisal research. Participants were asked to recall and describe emotional events and then questioned about their thoughts at the time in relation to the emotions experienced. In one fundamental respect, however, the research methodology adopted here differed from previous appraisal research. Instead of a survey design that relied on the use of questionnaires and statistical 
analysis to substantiate a set number of abstract appraisals, this investigation involved semistructured interviews followed by thematic analysis of the interview transcripts. The main reason for adopting a qualitative - as opposed to a quantitative - design was to identify cognitive appraisals for specific emotions grounded within the context of teaching rather than confirming abstract appraisals proposed by previous research. While the identification of abstract appraisals is of considerable interest for any theoretical discussion of the relationship between cognition and emotions, the identification of appraisals which are relevant to teaching in primary schools in England make a substantive contribution to educational research.

Robson (1993) points out that almost all qualitative research can be described as adopting a case study research strategy, as only a limited number of participants are subject to investigation and the quantity and nature of the data obtained does not lend itself to statistical analysis. Therefore, as Yin points out, instead of making "statistical generalizations" the purpose of qualitative research is to study a phenomenon in a particular setting in depth so that "analytical generalizations" (Yin 2003, p.32) can be made from how the phenomenon presents in a particular context. Following this approach the present study investigates the phenomenon of teachers' cognitive appraisal in the setting of eight inner city primary schools in England. All the institutions that took part were non-selective inner city schools that catered to the local population. The primary schools were similar in size as the number of pupils on roll varied between 200 and 250. According to the most recent OFSTED reports which were all completed within the four years preceding the study, all the schools had an ethnically diverse intake, and a well above national average number of pupils from economically disadvantaged backgrounds. 


\section{Data Collection and Analysis}

Data was collected by interviewing teachers regarding recent events at work where they experienced either frustration, anger, guilt, pride or a sense of feeling pleased or happy. Each participant was given the opportunity to describe a situation where they experienced one of these emotions and then to describe another event where they experienced one of the other emotions. Usually teachers recalled three to four emotional events in interviews that lasted between 30 to 45 minutes. Out of the 52 teachers interviewed 34 recalled events where they experienced anger. From amongst the 34 teachers there were 26 female teachers and 8 male teachers. This ratio was similar to that of the overall sample, which consisted of 41 female and 11 male teachers.

At the start of each interview participants were presented with the main interview question which invited them to recollect an emotional event that had occurred in the last 14 days. In particular, participants were asked to recall what they were thinking at the time and how this contributed to the emotions that they experienced. Each recollection of an emotional event was then followed by further clarification questions about their thoughts and how these may have contributed to their feelings at the time. These questions were then followed by more specific lines of enquiry informed by the abstract appraisal concepts already identified by appraisal research (Ellsworth \& Smith, 1988; Lazarus, 1991; Roseman, 2001; Scherer, 2001a). For instance, as previous appraisal research had identified the issue of responsibility and blame as an important appraisal dimension for anger, participants were asked whether they held anybody responsible for what had occurred, and if this contributed to the emotion/s that they experienced at the time. Moreover, participants were asked why at the time they blamed other/s for what had taken place.

Each interview was recorded and transcribed for data analysis. Thematic analysis was applied to the data (Boyatzis, 1998; Hayes, 1997; Joffe \& Yardley, 2004). Boyatzis (1998) 
maintains that thematic analysis can be guided by theory and previous research or it can be based on the data collected. On this occasion the thematic analysis was theory-led, in that it accepted the most fundamental theoretical assumption made by appraisal theorists. It was also previous research-led as it took into consideration abstract appraisals which had already been identified in previous appraisal research. The NVivo software package, produced by QSR for analysing qualitative data, was used to code the large amount of data collected. The first part of the data analysis, referred to as descriptive coding, involved summarising and labelling sections of text that related to participants' cognitive appraisals. Usually key phrases used by the participants to describe their thoughts and emotions were recorded verbatim in the descriptive codes to avoid interpretation at this stage. The purpose of descriptive coding was to make the raw data contained in the interview transcripts more manageable and accessible for interpretative coding. The interpretative analysis of the data then involved examining the descriptive codes and the data that the codes represented, to formulate higher and lower order interpretative themes or categories. This was achieved by sorting descriptive codes into overarching categories. For instance, in relation to anger descriptive codes such as I was treated unfairly, I felt betrayed, it was disrespectful, it was unfair to the children were at first placed in the overarching category of unacceptable behaviour of others, and then under unfair/unjust outcome. These interpretive categories were then analysed further to subdivide them into possible sub-categories. For instance the category of an unjust/unfair outcome was further subdivided into the sub-categories of me mistreated by other and significant others let down or upset (usually children).

This analytical process produced a small number of relatively abstract interpretative categories that are referred to here as appraisal dimensions, and a larger number of more descriptive contextual interpretative sub-categories that became appraisal dimension meanings (ADM). All of the ADM identified could be placed under the more abstract 


\section{Findings and Discussion}

Table 1 lists the appraisals identified in previous research alongside the appraisal dimensions and ADM for anger identified in this study.

\section{Location for Table 1}

On the basis of the interviews conducted and the thematic analysis of the data this study found support for the proposition that anger is associated with the appraisal dimensions of goal inconsistent/goal blockage, other/s blameworthy, injustice/unfairness and threat to self. The one proposed appraisal that this study did not find support for was that of potential power/control over the situation which had been described by Lazarus, (1991) Scherer (2001), and Roseman (2001). In contrast, the findings from this study suggest that while participants may have expressed their anger in order to gain control they did not seem to become angry, as such, to gain control. In other words, becoming angry with someone did not seem to involve wanting to gain control, but the expression of anger may have been mitigated by the desire to gain control over the situation. Perhaps this discrepancy between the findings of this study and previous research is a result of the reliance of the former on interviews rather than questionnaires and on the process of data analysis described above. By interviewing participants it was possible to examine emotional events as they unfolded over time rather that asking only closed questions, set out in a questionnaire, which focused on a participants' cognitive appraisal at a notional end point of an emotional event. 
Besides confirming most of the appraisal dimensions identified in previous research one of this investigation's most significant contributions is the identification of more contextual ADM. While appraisal dimensions are relatively abstract concepts not bound to any specific socio-cultural setting, ADM provide the more detailed and nuanced descriptions of each appraisal dimension within the context of primary school teaching. The appraisal dimension of goal inconsistent/goal blockage was usually associated with the teacher not being able to teach the class either because of pupil/s misbehaving in class and therefore disrupting the lesson or pupil/s making unreasonable demands on the teacher's time. The appraisal dimension of an unfair/unjust outcome was either associated teachers appraising themselves to have been mistreated in some way or significant others (usually their pupils) having been let down or upset by other adults. The appraisal dimension of threat to self was associated with teachers' own competence and/or their status in the school being directly or indirectly questioned by others. Finally the appraisal dimension of other/s blameworthy was associated with holding other/s personally responsible for a negative outcome.

In agreement with the findings of previous research all the descriptions of anger included the appraisal other/s blameworthy. The assignment of blame, in fact, appears to be at the core of the appraisal process for anger as holding others personally responsible for the other negative appraisals, such as an unjust/unfair outcome, seemed to bring about feelings of anger rather than some other negative emotion. Most importantly the assignment of blame required that the other person was judged to be accountable for his/her behaviour and its consequences, so that they could be held responsible for what they had done. In other words, 'they ought to have known better than to have behaved in this way'. In contrast, if the other person's actions could be construed as accidental, or because of a lack of experience or ability or some other mitigating justification then no blame was assigned. All teachers who took part avoided blaming their pupils for what they had done as their misconduct could be 
explained by a lack of ability or experience or other mitigating factors. This avoidance or delay in assigning blame was, however, rarely extended to other adults, who were held accountable and responsible for their actions.

In contrast to the appraisal other/s blameworthy always being associated with anger there were substantive variations in the extent to which other appraisals contributed to this emotion. At their most subtle these variations appeared at the level of ADM. For instance, when teachers talked about feeling threatened by others, they referred to their status within the school or their competence as teachers being called into question. Alongside these relatively subtle differences in ADM there was also one substantial and consistent variation in the combination of appraisal dimensions contributing to feelings of anger which depended on whether teachers were relating to other adults or they were interacting with their pupils in class. Indeed on the basis of variations in cognitive appraisal teachers seemed to experience quite different forms of anger in relation to their colleagues and parents than they did towards their pupils. While anger directed at pupils in class was almost always associated with the appraisal of ongoing goal blockage, frustration and the appraisal other/s blameworthy, anger in relation to adults was usually linked to the appraisals unjust/unfair outcome and/or threat to self and other/s blameworthy. Moreover, since anger in relation to pupils seemed to involve limited cognitive appraisal when compared to the extended cognitive appraisals associated with anger directed at other adults, these two forms of anger are referred to here as 'restricted anger' and 'elaborated anger'. The identification of these two forms of anger was one of the study's most substantial findings and they are therefore discussed in some detail here.

\section{Anger in relation to pupils: restricted anger}

Out of the 34 descriptions of becoming angry 12 involved events that started with teachers' feeling frustrated and then becoming angry with pupils in their class. In this 
investigation all the descriptions of anger directed at pupils included the appraisal of persistent goal blockage and the build up of frustration that then turned to anger as blame was assigned to one or more pupils. An illustration of this form of anger is provided by Patrick describing how he became angry with a pupil in his class.

Patrick: Child in class, asking the child to listen, knew perfectly well that during the first part of the lesson he would not be listening he would be fiddling, he finds it difficult to hold on to large pieces of information, so I would try and give him one or two instructions at a time. But on this particular day when again he decided not to listen I was frustrated ..... all my attention goes to him and then he cannot do it on his own. I go back to him, I show him how to do it, he gets it, I say you know how to do it, he goes away and he doesn't do it. And that is where the anger comes in, I stop and I say right I am not going to come and see you again, if you don't get this work done, and give him a threat of actually taking responsibility for your own learning, because I can't be here being your mummy and daddy, I am a teacher.

Patrick Yr5 teacher at VP school)

In this extract, Patrick describes how he is repeatedly prevented from teaching the class by this one pupil (goal blockage) resulting in him feeling increasingly frustrated. On this occasion the sense of frustration then turns into anger when he blames the child for taking up all of his time. The pupil was blamed for his lack of understanding and not doing the work because "he decided not to listen", making him personally responsible for taking up the teacher's time. Patrick then immediately expresses his anger by giving "him a threat of" taking responsibility for his own learning and telling him that he is his teacher and not his "mummy and daddy".

The descriptions of anger in class by other teachers followed a similar sequence. They included a build up of frustration over time that then turned into anger as blame was assigned to one or more pupils. The anger was also expressed immediately possibly to try and change the situation or simply as a way to vent intense feelings of frustration that had built- up over 
time. This form of anger directed at pupils is referred to here as 'restricted anger' as it did not seem to involve more substantial or complex cognitive appraisal than that of persistent goal blockage and the assignment of blame. Moreover, anger directed at pupils was not longlasting but would dissipate and be replaced by another emotional state once the anger had been expressed. Indeed most teachers (including Patrick) talked about feeling guilty or disappointed with themselves after having lost their temper in class. As was mentioned earlier in this investigation all the descriptions of anger in class followed this sequence resulting in restricted anger that was expressed at the time. Yet, the identification of this type of anger does not preclude other forms of anger being experienced in class, associated with a more complex set of appraisals. Indeed, there must also be occasions when anger directed at a pupil is based on a perceived threat to self and a sense of having been mistreated by one or more pupils. Although the focus here is on frustration turning into anger, it is important to point out that out of 41 descriptions of feeling frustrated in class as a result of pupils' behaviour only 12 included the apportioning of blame and becoming angry. When teachers did describe becoming angry they often made reference to feeling tired, hungry or the event taking place at the end of a teaching session. It is as if feeling slightly unwell or tired made them less able to contain their frustration.

In support of these findings Frijda has suggested that anger can be initiated by a very basic form of cognitive appraisal which he describes as "acute goal interference" (Frijda, 1993, p. 374). According to Frijda an individual may first become frustrated or experience some other form of distress that is very close to anger, associated with "acute goal interference". At a later stage this distress becomes anger as the person blames somebody or something for what has happened on the basis of very limited or restricted cognition. That anger may be based on goal blockage and frustration alone is also maintained by Parkinson (1999) and Berkowitz \& Harmon-Jones (2004), who have proposed that the assignment of 
blame may in fact occur after the person has already started to become angry. Parkinson refers to such anger based on goal blockage and frustration as "unreasonable anger" (Parkinson, 1999, p. 353). Whether such unreasonable anger actually precedes the apportioning of blame is debatable, as there is no firm evidence for either sequence. At this point all that can be said is that in circumstance that involve the build up of frustration, the assignment of blame and the experience of anger seem to occur almost simultaneously.

\section{Anger in relation to other adults: elaborated anger}

Out of the 34 teachers who recalled feeling angry 22 described situations in which they became angry with other teachers or parents. On such occasions the appraisals associated with anger did not simply include goal /goal blockage and other/s blameworthy but also the appraisal dimensions of unjust/unfair outcome and threat to self. Moreover, participants were usually not in any negative emotional state, such as frustration, before they became angry. In these circumstances anger seemed to derive from the realisation that somebody else, who could be held accountable, had acted unfairly or unjustly and/or posed a threat to one's professional or personal self. Whenever teachers experienced such anger towards other adults they did not express their anger at the time. Instead, they seemed to engage in ongoing cognitive appraisal that did not reduce their anger but maintain and cognitively define it.

In order to provide a detailed portrayal of the appraisals associated with elaborated anger the appraisal dimensions unfair/unjust outcome and threat to self are described in some detail. The appraisal dimension unfair/unjust outcome consists of the ADM me mistreated by others and that of let down or upset significant others (usually children). The former appraisal refers to the perception of having been treated unfairly/unjustly and/or disrespectfully. In order to illustrate this sense of mistreatment by others two examples from 
Researcher: Why was it this time that you actually got angry?

Daphne: ... I think when she directed it at me personally, when she said you are a shit teacher because you can't look after a coat. When it became personal, it was upsetting and then Ifelt angry, someone actually talking to me in that way.

(Daphne Yr2 teacher at NP school)

Researcher: What made you angry about that?

Holly: It's just the idea that I should be responsible for a 5 year olds sweatshirt, if the parent does all the things that we ask them to do, write their name in, teach the child because I think it's the parents job to teach the child to look after their own clothes and that kind of thing and I think the amount of work that I do at school, I'm teaching their child to read and write and count and all the thousands of other things that we teach them to do and the one thing they can come and talk to me about is that the hood has fallen off their coat and where is it? That makes me feel really angry.

(Holly reception class teacher at LP school)

Both Daphne and Holly perceived themselves to have been judged unfairly/unjustly and also treated disrespectfully. Daphne considered being called a "shit teacher" to be disrespectful on a personal level, and Holly made it clear how unfair the parent's comments were by listing all the things teachers do for their children that often pass unnoticed. From both interviews it transpired that the teachers did not express their anger at the time but kept their feelings under control until they were able to remove themselves from the situation.

Besides teachers feeling angry for having been mistreated by other adults there were also times when they seemed to experience anger on behalf of their pupils. Three teachers described feeling angry with their colleagues when they thought that they had let down or upset their pupils (let down and/or upset significant others). An illustration of this is 
provided by the special educational co-ordinator at EP school who described how she became angry when other teachers did not differentiate the maths lesson for children with special educational needs (SEN), for whom she had overall responsibility.

Julie: We [the management team] monitored the Maths books in the whole of the school and what became evident was that ... there is a huge mismatch [between the work that the children are given and what they are able to do]. And I felt that with the teachers who were doing this it was not due to lack of ability to differentiate, it was lack of being bothered I thought....... I felt it personally that they were not meeting the needs of the kids that I have the main priority over. And those kids would fail.....

(Julie, SENCO at EP school)

Here Julie became angry with her colleagues for not bothering to differentiate the curriculum and therefore putting at risk the chances of success of children with special educational needs. As in the cases describe above, Julie did not express her anger at the time.

The appraisal dimension of threat to self refers to situations that are appraised as threatening to beliefs that the individual holds about him or herself. This appraisal is thought to apply when substantive beliefs about the self are put into question by particular events and by the actions of others. For instance, in the above extract Julie suggests that the lack of engagement with SEN pupils by colleagues also represented a threat to her personal and professional self. She suggests this by explaining how she "felt it personally" when children for whom she is has overall responsibility were being let down.

Two sets of beliefs regarding the self appeared to be particularly important to the teachers taking part. The first was related to their perception of the appropriateness of their status in the school hierarchy and the second concerned their professional competence as educators. It was the perceived threat to these beliefs brought about by the action of other adults (summarised by the ADM own status/competence threatened by others) that often contribute to elaborated anger. An illustration of this appraisal is provided by Delia, the 
reception class teacher from VP school, who felt angry when she realised that a senior colleague had not consulted with her on the distribution of resources for key stage one.

Researcher: Why was it so important to you [the other teacher not consulting with her] that you had to go and see somebody about it. Why did you not just think ah well, let her get on with it.

Delia: Mmm, because I felt annoyed, thought it was wrong, I felt a bit threatened, maybe, my position, I thought that she was wrong.

Researcher: You said you felt threatened.

Delia; In my position as a teacher I felt threatened of, if she does not want to know what I think.

Researcher: You said she threatened your position as a teacher. What position is that?

Delia: My experience, I am more experienced in the early years than she is....

(Delia reception class teacher at VP school)

Here Delia describes how she considered the behaviour of the more senior colleague to challenge her own position and status as a teacher with extensive experience in working with the younger children in the school. She appraised the other teacher not consulting with her as a threat to how she perceived her status in the school.

So far the appraisal dimensions and their ADM have been considered separately in order to discuss them in some detail. Yet, in most situations elaborated anger seemed to be based on a combination of appraisals that included an unfair/unjust outcome and a perceived threat to self rather than one particular appraisal. Moreover, once angry teachers continued to appraise the situation and it is this continued appraisal - involving different ADM - that seemed to maintain or even enhance the experience of being angry. An illustration of this continued appraisal over time is provided in Figure 1. On this occasion Doris, a year 6 teacher at NP School, became angry when a less experienced and younger member of staff informed her and colleagues that she had been promoted. Her anger was not expressed at the 
time but was left unresolved, as is shown by her continued feelings of anger during the interview, which was conducted the day after the event occurred. 


\section{Location for Figure 1}

This interview extract illustrates how the appraisals did not just contribute to the causation of anger but also appeared to sustain and define it. For instance, the appraisal $m e$ mistreated by others is revisited and expanded upon by Doris several times. In section 1 the promotion of this younger woman is appraised as unjust/unfair in relation to herself. Then in section 3 her conduct is considered to have been disrespectful and finally, in sections 8-11 the whole situation is appraised in terms of class and racial discrimination. It is the addition of this last appraisal that in particular seemed to maintain and even increase her feelings of anger. Similarly, the appraisal of threat to self is also revisited and dwelled upon several times as Doris re-emphasises the threat posed to her personally by this promotion in sections 1, 7, 8-9 and 52. Indeed, as Doris became angry this emotion seemed to focus her thoughts on finding additional negative appraisals to support her anger. The suggestion here is not that the critical thoughts and accusations of discrimination when angry are not legitimate. Rather, there is a recognition that certain ways of evaluating the situation come to mind more readily when the person is feeling angry. Overall, the extract from Doris's interview illustrates how the anger initiated by a colleague receiving a promotion seemed to be maintained and elaborated upon by an ongoing appraisal over time.

\section{Conclusion}

The findings suggest that teachers experienced different forms of anger depending on whether they were relating to children in class or other adults. Restricted anger in relation to pupils seemed to emerge when persistent goal blockage resulted in a build up of frustration that then turned in to anger when blame was assigned. Most often teachers became angry 
when the persistent tension between the needs of the class and the demands of individual pupils became too much to bear. It was this tension and frustration that built up over time and the teachers own ability to manage these, rather than substantive cognitive appraisal, which seemed to determine whether a teacher became angry in class. These findings support those of Sutton (2000, 2002), who concluded that teachers' anger in class is mostly based on the appraisal of persistent goal blockage and the build up of frustration.

By contrast, elaborated anger towards other adults was linked to the more complex appraisals of somebody being blamed for having taken an avoidable course of action that may have been perceived as a threat to aspects of self, and resulted in an unfair/ unjust outcome for oneself or the children in one's class. Moreover, since such anger was not expressed teachers were more likely to maintain and extend their feelings of anger by elaborating and adding to the appraisals associated with that emotion.

This study is of practical relevance as its findings provide primary school teachers with considerable insight into the different forms of anger that they are likely to experience in their work. Most importantly, the findings suggest that teachers experience their most profound and extensive feelings of anger in relation to colleagues and parents rather than their pupils. Indicating that if senior teachers and administrators wish to maintain the well being and effectiveness of their teaching staff they should not only aim to support them in their work with pupils in class but also attend to their working lives and relationships outside of the classroom. In addition, this investigation is also of substantial relevance to future educational research as it illustrates how the study of teachers' thoughts and emotions can help us gain a better understanding of teachers working lives. The qualitative approach adopted here to study the relationship between cognitive appraisals and anger provides a good illustration of how such research can provide insights into participants' perceptions of themselves and their work. 


\section{References}

Berkowitz, L., \& Harmon-Jones, E. (2004). Towards an understanding of the determinants of anger. Emotion, 4(2), 107-130.

Boyatzis, R. E. (1998). Transforming qualitative information: Thematic analysis and code development. Thousand Oaks: Sage.

Ellsworth, P. C., \& Smith, C. A. (1988). From appraisal to emotion: Differences amongst unpleasant feelings. Motivation and Emotion, 12, 271 - 302.

Frijda, N. H. (1993). The place of appraisal in emotion. Cognition and Emotion, 7, 357-388.

Frijda, N. H., \& Zeelenberg, M. (2001). Appraisal:What is the dependent ? In K. R. Scherer, A. Schorr \& I. T. Johnstone (Eds.), Appraisal process in emotion: theory, method, research. New York: Oxford University Press.

Hargreaves, A. (1998). The emotional practice of teaching. Teaching and Teacher Education, 14(8), 845-854.

Hayes, N. (1997). Theory-led thematic analysis: Social identification in small companies. In N. Hayes (Ed.), Doing qualitative analysis in psychology (pp. 93-113). Kings Lynn: Psychology Press.

Joffe, H., \& Yardley, L. (2004). Content and thematic analysis. In D. F. Marks \& L. Yardley (Eds.), Research methods for clinical and health psychology. London: Sage.

Kelchtermans, G. (2005). Teachers' emotions in educational reforms: Self-Understanding, vulnerable commitment and micropolitical literacy. Teaching and Teacher Education, $21,995-1006$.

Lasky, S. (2005). A sociocultural approach to understanding teacher identity, agency and professional vulnerability in a context of secondary school reform. Teaching and Teacher Education, 21, 899-916.

Lazarus, R. S. (1991). Emotion and adaptation. New York: Oxford University Press.

Liljestrom, A., Roulston, K., \& DeMarrais, K. (2007). "There is no place for feeling like this in the workplace": Women teachers' anger in school settings. In P. A. Schutz, D. I. Cross, J. Y. Hong \& J. N. Osbon (Eds.), Emotion in Education. London: Elsevier.

Mikula, G., Scherer, K. R., \& Athenstaedt, U. (1998). The role of injustice in the elicitation of differential emotional reactions. Personality and Social Psychology Bulletin, 24(7), 769-783.

Nias, J. (1996). Thinking about feeling: the emotions in teaching. Cambridge Journal of Education, 26(3), 293-306.

Parkinson, B. (1999). Relations and dissociations between appraisal and emotion ratings of reasonable and unreasonable anger and guilt. Cognition and Emotion, 1999(4), 347385.

Poulou, M., \& Norwich, B. (2002). Cognitive, emotional and behavioural responses to students with emotional and behavioural difficulties: a model of decision-making. British Educational Research Journal, 28(1), 111-138.

Robson, C. (1993). Real world research. Oxford: Blackwell.

Roseman, I. J. (2001). A model of appraisal in the emotion system. In K. R. Scherer, A. Schorr \& I. T. Johnstone (Eds.), Appraisal process in emotion: Theory, method, research. New York: Oxford University Press.

Roseman, I. J., Antoniou, A. A., \& Jose, P. E. (1996). Appraisal determinants of emotions: Constructing a more accurate and comprehensive theory. Cognition and Emotion, 10, 241-277. 
Scherer, K. R. (1993). Studying the emotion-antecedent appraisal process: An expert system approach. Cognition and Emotion, 7(3/4), 325-355.

Scherer, K. R. (2001a). Appraisal considered as a process of multilevel sequential checking. In K. R. Scherer, A. Schorr \& I. T. Johnstone (Eds.), Appraisal processes in emotions: Theory, method, research (pp. 92 -120). New York: Oxford University Press.

Scherer, K. R. (2001b). The nature and study of appraisal: A review of the issues. In K. R. Scherer, A. Schorr \& I. T. Johnstone (Eds.), Appraisal processes in emotions: Theory, method, research. New York: Oxford University Press.

Schorr, A. (2001). Subjective measurement in appraisal research: Present state and future perspectives. In K. R. Scherer, A. Schorr \& I. T. Johnstone (Eds.), Appraisal processes in emotions: Theory, method, research. New York: Oxford University Press.

Shweder, R. A. (1993). Everything you ever wanted to now about cognitive appraisal theory without being conscious of it. Psychological Inquiry, 4, 322-342.

Smith, C. A., \& Lazarus, R. S. (1993). Appraisal components, core relational themes, and the emotions. Cognition and Emotions, 7(3/4), 233-269.

Sutton, R. E. (2000). The emotional experiences of teachers. Paper presented at the Annual Meeting of the American Educational Research Association, New Orleans.

Sutton, R. E. (2002). Middle school teachers' day-to-day experiences of anger and frustration. Paper presented at the Annual Conference of the American Educational Research Association, New Orleans.

Sutton, R. E. (2004). Emotion regulation goals and strategies of teachers. Social Psychology of Education, 7, 379-398.

Sutton, R. E. (2007). teachers' anger, frustration and self-regulation. In P. A. Schutz \& P. Reinhard (Eds.), Emotion in Education. London: Elsevier.

van Veen, K., \& Sleegers, P. (2006). How does it feel? Teacher's emotions in a context of change. Journal of Curriculum Studies, 38(1), 85-111.

Yin, R. K. (2003). Case study research: Design and Method (2nd ed.). London: Sage.

Zembylas, M. (2003). Emotions and teacher identify: a postructural perspective. Teachers and teaching: theory and practice 9(3), 213-238. 


\section{Table 1}

\begin{tabular}{|c|c|c|}
\hline $\begin{array}{l}\text { Appraisals for anger identified in } \\
\text { previous research }\end{array}$ & $\begin{array}{l}\text { Appraisal Dimensions } \\
\text { identified in this study }\end{array}$ & $\begin{array}{l}\text { Appraisal Dimension } \\
\text { Meanings (ADM) identified } \\
\text { in this study }\end{array}$ \\
\hline $\begin{array}{l}\text { Goal Inconsistent/Goal Blockage } \\
\text { has been identified by all previous } \\
\text { appraisal researchers (Ellsworth \& } \\
\text { Smith, 1988; Roseman, 2001; } \\
\text { Scherer, 2001a; Smith \& Lazarus, } \\
\text { 1993) }\end{array}$ & $\begin{array}{l}\text { Goal Inconsistent/goal } \\
\text { blockage }\end{array}$ & $\begin{array}{l}\text { Prevented from attaining a } \\
\text { desired goal (usually in } \\
\text { relation to teaching and } \\
\text { learning in class) }\end{array}$ \\
\hline $\begin{array}{l}\text { injustice/unfairness } \\
\text { Ellsworth and Smith (1988) and } \\
\text { Mikula and Scherer et al (1998) }\end{array}$ & Unjust/ unfair outcome & $\begin{array}{l}\text { - Me mistreated by others } \\
\text { - let down or upset } \\
\text { significant others (usually } \\
\text { children) }\end{array}$ \\
\hline $\begin{array}{l}\text { Threat to self (or ego identify) } \\
\text { Lazarus (1991) }\end{array}$ & Threat to self & $\begin{array}{l}\text { - Own status/competence } \\
\text { threatened by others. }\end{array}$ \\
\hline $\begin{array}{l}\text { other/s blameworthy } \\
\text { or its equivalent has been proposed } \\
\text { by all previous appraisal research } \\
\text { (Ellsworth \& Smith, 1988; } \\
\text { Roseman, 2001; Scherer, 2001a; } \\
\text { Smith \& Lazarus, 1993) }\end{array}$ & Other/s blameworthy & $\begin{array}{l}\text { - Personal responsibility for } \\
\text { negative outcome assigned } \\
\text { to other/s }\end{array}$ \\
\hline $\begin{array}{l}\text { Potential to gain power/control over } \\
\text { the situation (Roseman, 2001; } \\
\text { Scherer 2001; Lazarus 1991) }\end{array}$ & $\begin{array}{l}\text { The appraisal was not } \\
\text { identified in this study }\end{array}$ & \\
\hline
\end{tabular}

Table 1: Appraisals for anger identified in previous research and the Appraisal Dimensions and Appraisal Dimension Meanings (ADM) identified in this study. 
\begin{tabular}{|l|}
\hline Transcript \\
(1)Doris: Yesterday I just felt really angry. The reason being \\
in the teaching profession, this is the truth of it, is every year \\
you go up one step up the ladder. And being my third year I \\
found out yesterday that a girl who is teaching at this school in \\
her second year, seemed to be being pushed up a bit. So I felt \\
angry because from what's been said by her that she'd be \\
getting more money than me in September and she'd be given \\
more responsibility. I just felt angry yesterday because I felt \\
that what I do wasn't being recognised and that sometimes you \\
just feel that if your face doesn't fit then you won't get very far \\
and its quite a battle and for all the hard work that I do.... I've \\
got two young children of my own under the age of 6. I'm up at \\
6.30 every morning and I do my best and I just felt angry \\
because I'm not being recognised for the job that I do. And \\
someone who is not fantastic but whose father happens to be a \\
head master seems to be treated differently..... \\
(2) Researcher: Was this unexpected?
\end{tabular}

(3) Doris: It's how it was done, you see. You know you work in a certain environment and things happen that shouldn't be done the way they are. She's come out and said she was getting a pay raise, in this kind of job you don't need to talk about, discuss your wages. It's quite funny because you know every year its common knowledge every year you go up a point. But she had to come into the staff room saying next year she's doing this and that and she's going to be getting more money. More recently things have been said about her and she comes in and starts telling the whole staff room how great she is and what's been said about her. And then that was the final straw. I was so angry I went home angry.

(4) Researcher: You are still angry.

(5) Doris: I'm still very angry.......

(6) Researcher: What are you going to do with this anger? (7) Doris: Redirect it somewhere else. Just try and get rid of it because it's not healthy anyway for me. I've got two kids, I've got my own life outside work. What it is, is that I came in to this profession quite late on. I had a child before I came here. I'd lived, basically. I didn't just come from university. This is my career, this is my future, I love this job. So I take it very seriously. Things that won't affect other teachers affect me more because this is what I want to do. I'm getting old now, this is not a game, this is my job and I love doing my job.
Appraisal Dimension and ADM

\section{Unjust/Unfair Outcome}

Me mistreated by others: treated unfairly/ unjustly by others $\&$

\section{Threat to self}

Own status/competence threatened by new younger teacher.

(In particular illustrated by "that a girl who is teaching at this school")

\section{Unjust/Unfair Outcome}

Me mistreated by others: treated disrespectfully by others (the way she had behaved)) \&

\section{Other/s Blameworthy}

Personally responsibility for negative outcome assigned to others (She should have known better than to behave in this way. In particular illustrate by “in this kind of job you don't need to talk about, discuss you wages")

\section{Threat to self}

Own status/competence threatened by younger teacher (in particular illustrated by " $I$ am getting old now, this is not a game, this is my job") 
(8) Researcher: Did you consider her to be a threat to you? (9) Doris: Not in the sense that she was going to get a job that I wanted, but in that she can walk in here after I've been here, she is not that qualified in some areas, and instantly being given, or saying, that she's basically going to be given some sort of management role and being given more money when I've actually gone and asked for money and have been told I have to prove myself at the beginning and I walk away and said fine, if I have to prove myself I will do that. And for someone to get it just like that.... .I live my life by what I've achieved is through my own hard work, not because of who I know. That's why I got angry.

(10) Researcher: There's an unfair aspect to this.

(11) Doris: Of course it is. It's not right... Also I think it's also a class divide because I'm working class. I'm black, I'm working class, she's white, she's middle class, everything seems to be easy for her. I have to struggle and that's the difference. I struggle but she seems to get everything landed on a plate.

That's the anger.

Then in the subsequent part of the interview when talking about being angry with a child in class, she made the following point:

(52) Doris: .it's a different type of anger [referring to the anger described above] because the anger that I had yesterday was more personal and it was more to do with what I feel really my future, my future career, my profession. This was a child just trying to push me but it wasn't threatening..... Researcher: You say it's very different to the other anger? Doris: Its different, he's [the child] not threatening me.

53. Researcher: How was the other time threatening?

54. Doris: It was threatening to me in school, professionally as a teacher, teaching is important to me, it's not just a job to me.

Figure 1: Extract from the interview with Doris (Yr6 teacher at NP school) describing the reasons for her anger alongside appraisal dimensions and ADM. 